\title{
Rate of Urinary Retention in Adults With Down Syndrome: A Prospective Study
}

\author{
Brian Chicoine, MD, and Suela Sulo, MSc
}

Purpose: Down syndrome (DS) is associated with a higher incidence of many medical conditions, but little information regarding urinary retention exists. We assessed the urinary retention rates in a group of adults with DS and compared the characteristics of patients with and without urinary retention.

Methods: A prospective observational study of adults with DS was conducted. Patients were recruited at their regularly scheduled medical appointments. A noninvasive bladder volume instrument, the BladderScan BVI 3000, was used to determine the bladder volume after voiding.

Results: We enrolled 66 patients (mean age, 36.6 years). of these, 6 patients $(9 \%)$ had urinary retention. Patients with urinary retention were significantly older $(46.5$ vs 35.6 years old; $P=.022)$ and had higher rates of urinary frequency $(P=.003)$ than patients without urinary retention. No other differences were statistically significant. Of the 6 patients with urinary retention, most $(83.3 \%)$ were men and 45 years of age or older. Urinary frequency was the most common symptom associated with the diagnosis of urinary retention.

Conclusions: The reported frequency and symptoms of urinary retention in adults with DS who are older than 45 years of age can be used to guide further clinical evaluation for urinary retention. ( $\mathrm{J}$ Am Board Fam Med 2015;28:115-117.)

Keywords: Down Syndrome, Urinary Retention

The life expectancy of people with Down syndrome (DS) has increased to 60 years of age. ${ }^{1}$ With increasing longevity comes an increased risk of health issues; however, clinical guidelines for diagnosing and managing these issues in adults with DS have received little attention. ${ }^{1}$

In particular, information on the urinary system is quite limited. Anecdotal reports and clinical studies have suggested a potential association between DS and urinary retention. ${ }^{2}$ Unrecognized, chronic urinary retention can lead to urinary tract infec-

This article was externally peer reviewed.

Submitted 16 February 2014; revised 24 June 2014; accepted 27 June 2014.

From the Adult Down Syndrome Center and Family Medicine Residency, Advocate Lutheran General Hospital, Park Ridge, IL (BC); and the James R. and Helen D. Russell Institute for Research \& Innovation, Advocate Lutheran General Hospital, Park Ridge, IL (SS).

Funding: This study received funding from the Advocate Lutheran General Health Partners Endowment Grant (343-10).

Conflict of interest: none declared.

Corresponding author: Brian Chicoine, MD, Adult Down Syndrome Center, Advocate Lutheran General Hospital, 1610 Luther Lane, Park Ridge, IL 60068 (E-mail: brian.chicoine@advocatehealth.com). tions, bladder damage, hydronephrosis, and kidney damage/failure. ${ }^{3}$ The potential for unrecognized urinary retention may be high in people with DS because of limitations in communication skills. This study aimed to identify the frequency and symptoms of urinary retention in adults with DS, which may provide information to assist in early diagnosis and improve health screening recommendations.

\section{Methods}

A prospective observational study of adults with DS was conducted. Eligible patients were recruited during their regularly scheduled medical appointments between June 2011 and October 2012. Approval was obtained by the Advocate Health Care Institutional Review Board. Consent was obtained from the patient (if they were their own legal guardian) or from the patient's legal guardian. Assent was obtained from all patients whose legal guardian signed the consent.

The patient or guardian completed a brief questionnaire about symptoms. Medical records were reviewed to obtain demographic data, medical his- 
Table 1. Comparisons Between Participants With and Without Urinary Retention

\begin{tabular}{|c|c|c|c|}
\hline Variables & $\begin{array}{l}\text { Urinary } \\
\text { Retention } \\
(\mathrm{n}=6)\end{array}$ & $\begin{array}{l}\text { No Urinary } \\
\text { Retention } \\
(\mathrm{n}=60)\end{array}$ & $\begin{array}{c}P \\
\text { Value }\end{array}$ \\
\hline Age, mean (SD) & $46.5(11.5)$ & $35.6(10.8)$ & $.022^{*}$ \\
\hline BUN, mean (SD) & $16.7(5.5)$ & $16.0(3.5)$ & .649 \\
\hline Creatinine, mean (SD) & $1.0(0.1)$ & $1.0(0.2)$ & .644 \\
\hline $\begin{array}{l}\text { Bladder volume, mean } \\
\text { (SD) }\end{array}$ & $184.8(78.8)$ & $15.3(22.2)$ & $.000^{\dagger}$ \\
\hline Male sex & $5(83.3)$ & $33(55.0)$ & .230 \\
\hline White race & $6(100)$ & $52(86.7)$ & .923 \\
\hline Difficulty urinating $^{\ddagger}$ & & & .588 \\
\hline None/never & $3(50.0)$ & $47(77.0)$ & \\
\hline Rarely & $1(16.7)$ & $4(6.6)$ & \\
\hline Occasionally & $1(16.7)$ & $4(6.6)$ & \\
\hline Frequently & $1(16.7)$ & $4(6.6)$ & \\
\hline $\begin{array}{l}\text { Urinary incontinence } \\
\text { during the day }\end{array}$ & & & .589 \\
\hline None/never & $5(50.0)$ & $43(71.7)$ & \\
\hline Rarely & $1(33.3)$ & $9(15.0)$ & \\
\hline Occasionally & $0(16.7)$ & $7(11.7)$ & \\
\hline Frequently & 0 & $1(1.7)$ & \\
\hline $\begin{array}{r}\text { Urinary incontinence } \\
\text { during the night }\end{array}$ & & & .795 \\
\hline None/never & $5(83.3)$ & $45(75.0)$ & \\
\hline Rarely & $1(16.7)$ & $11(18.3)$ & \\
\hline Occasionally & 0 & $4(6.7)$ & \\
\hline Frequently & 0 & 0 & \\
\hline Urinary frequency & & & $.003^{\dagger}$ \\
\hline None/never & $1(16.7)$ & $41(68.3)$ & \\
\hline Rarely & $1(16.7)$ & $10(16.7)$ & \\
\hline Occasionally & 0 & $6(10.0)$ & \\
\hline Frequently & $4(67.0)$ & $3(5.0)$ & \\
\hline Infrequent urination & & & .696 \\
\hline None/never & $4(66.7)$ & $32(53.3)$ & \\
\hline Rarely & $1(16.7)$ & $8(13.3)$ & \\
\hline Occasionally & 0 & $12(20.0)$ & \\
\hline Frequently & $1(16.7)$ & $8(13.3)$ & \\
\hline Abnormal pain & & & .209 \\
\hline None/never & $4(66.7)$ & $46(76.7)$ & \\
\hline Rarely & $1(16.7)$ & $9(15.0)$ & \\
\hline Occasionally & 0 & $4(6.7)$ & \\
\hline Frequently & $1(16.7)$ & $1(1.7)$ & \\
\hline $\begin{array}{l}\text { Uncharacteristic mood } \\
\text { changes }\end{array}$ & & & .956 \\
\hline None/never & $4(66.7)$ & $37(61.7)$ & \\
\hline Rarely & $1(16.7)$ & $10(16.7)$ & \\
\hline Occasionally & $1(16.7)$ & $10(16.7)$ & \\
\hline Frequently & $0(16.7)$ & $3(5.0)$ & \\
\hline $\begin{array}{c}\text { Uncharacteristic } \\
\text { behavioral } \\
\text { changes }^{\ddagger}\end{array}$ & & & .899 \\
\hline None/never & $3(50.0)$ & $35(58.3)$ & \\
\hline
\end{tabular}

Continued
Table 1. Continued

\begin{tabular}{lccc}
\hline Variables & $\begin{array}{c}\text { Urinary } \\
\text { Retention } \\
(\mathrm{n}=6)\end{array}$ & $\begin{array}{c}\text { No Urinary } \\
\text { Retention } \\
(\mathrm{n}=60)\end{array}$ & $\begin{array}{c}P \\
\text { Value }\end{array}$ \\
\hline Rarely & $1(16.7)$ & $8(13.3)$ & \\
Occasionally & $2(33.3)$ & $12(20.0)$ & \\
Frequently & 0 & $4(6.7)$ & \\
Intelligibility by & & & .978 \\
$\quad$ familiar others & & $2(3.3)$ & \\
None/never & 0 & $1(1.7)$ & \\
Rarely & 0 & $8(13.3)$ & \\
$\begin{array}{l}\text { Occasionally } \\
\text { Frequently }\end{array}$ & $1(16.7)$ & $49(81.7)$ & \\
Intelligibility by & $5(83.3)$ & & .117 \\
$\quad$ unfamiliar others & & $5(8.3)$ & \\
None/never & $1(16.7)$ & $10(16.7)$ & \\
Rarely & $3(50.0)$ & $21(35.0)$ & \\
$\begin{array}{l}\text { Occasionally } \\
\text { Frequently }\end{array}$ & $2(33.3)$ & $24(40.0)$ & \\
Bladder infections & 0 & $1(1.6)$ & 1.000 \\
Wears Depends & 0 & $4(6.6)$ & 1.000 \\
History of bladder & 0 & 0 & $\mathrm{NA}$ \\
$\quad$ damage & 0 & & \\
History of kidney & & & \\
$\quad$ damage & 0 & & \\
\hline & & & \\
\hline
\end{tabular}

Data are $\mathrm{n}(\%)$ unless otherwise indicated.

${ }^{*} P<.05$.

${ }^{\dagger} P<.01$.

${ }^{\ddagger}$ Numbers do not add up to $100 \%$ because of missing data.

BUN, blood urea nitrogen; NA, not applicable; SD, standard deviation.

tory, results of recent blood tests, and current medications. Patients who were taking medications associated with urinary retention were excluded.

Patients were instructed to urinate and empty the bladder completely. A noninvasive bladder volume instrument, BladderScan BVI 3000, was used to assess and calculate bladder volume after voiding. Urinary retention was defined as a bladder volume of $\geq 100 \mathrm{~mL}$. The urinary retention rate was calculated, and the characteristics of patients with and without urinary retention were compared.

\section{Results}

Sixty-six patients with a mean age of 36.6 years were enrolled in the study. Urinary retention was found in 6 patients $(9 \%)$. In these patients, the mean age and urinary frequency rate were significantly higher than those of patients without urinary retention (Table 1). No other statistically significant differences between the groups were found. Of 
the 6 patients with urinary retention, most $(83.3 \%)$ were male and $\geq 45$ years old.

\section{Discussion}

This study aimed to understand the incidence and presentation of urinary retention in adults with DS. Urinary retention was found in $8.7 \%$ of patients, which is similar to the frequency reported for adults with moderate to severe intellectual disabilities $^{4}$ but higher than the frequency reported for adults without DS. ${ }^{5}$ Urinary retention occurred in both men and women, which also supports previous findings, ${ }^{4}$ and was more common in patients $>45$ years old. Urinary frequency was the main symptom associated with the diagnosis of urinary retention. Therefore, in patients with DS with urinary frequency, particularly in those $>45$ years old, urinary retention should be considered.

This study has several limitations. Bladder scans were performed only once in each patient, which may have missed variations in bladder voiding on other occasions. In addition, prostate examinations were not performed on male patients; therefore, unrecognized prostate conditions may have confounded the data. Finally, the sample size was relatively small, and results may not be generalizable to other adult patients with DS. Despite these limitations, to our knowledge this is the first study assessing the urinary retention rate of adults with DS.

\section{Conclusion}

These data support further study to evaluate longterm complications at different volumes of urinary retention and to assess the cost-to-benefit ratio of bladder scanning as a screening tool in people with DS who are $>45$ years old.

The authors thank Laura Chicoine for her assistance with data collection and literature review.

\section{References}

1. Malt EA, Dahl RC, Haugsand TM, et al. Health and disease in adults with Down syndrome. Tidsskr Nor Laegeforen 2013;133:290-4.

2. Chicoine B, McGuire D. The guide to good health for teens \& adults with Down syndrome. Bethesda, MD: Woodbine House; 2010.

3. deWaal KH, Tinselboer BM, Evenhuis HM, Penning C. Unnoticed post-void residual urine volume in people with moderate to severe intellectual disabilities: prevalence and risk factors. J Intellect Disabil Res 2009;53:772-9.

4. Kasper DL, Tinsley RH. Harrison's principles of internal medicine. New York: McGraw-Hill, Medical Publishing Division; 2005.

5. Selius BA, Subedi R. Urinary retention in adults: diagnosis and initial management. Am Fam Physician 2008;77:643-50. 